\title{
EMRS debate report
}

Dinner on Friday was followed by a light-hearted debate with a serious motion; 'This house aspires to 24-hour accident and emergency (A\&E) consultant presence'. Opening the debate in favour of the motion, Tom Beattie referred to the original ideals set out in the 1960s when consultants were appointed to 'manage the department, educate and train, conduct research and audit performance'. When a consultant is present on the 'shop floor' his opinion is sought. When he is not, the junior doctor has to decide for himself. This leads to many patients returning to review clinics unnecessarily. The best trauma audit figures from the Scottish Trauma Audit Group come from the departments with the best consultant presence. Ten minutes to arrive in the department when on call from home is too long for a cardiac arrest or a seriously injured child. It is no longer acceptable to work nine to five and be on call from home. Stephen Cusack opposing the motion felt that the motion was not rational, or economically viable. While recognizing the groundswell of opinion in favour of the motion he observed that it would require $50 \%$ of the UK graduates to specialize in A\&E medicine to staff all the departments with consultants. The most skillful and able people are required in A\&E departments, but this does not necessarily mean consultants. Consultants are far more than a pair of hands on the shop floor. They undergo arduous training to lead and hone the specialty and ensure optimum management for the patients. It does not require a consultant present for 24 hours to see the four patients that are managed in the resuscitation room every day.

Ivan Phair seconded the motion by reiterating that 10 minutes is too late in critical illness and drew a golfing analogy of the professional standing by the amateur leading to an uplifting of the amateurs game.
Chris Cutting opposed the motion by arguing that it may be ideal to have a consultant present in the department 24 hours a day but is it practical? He recognized the need to have staff that could carry out all the life saving tasks present all the time, but to have consultants would mean an enormous caseload to make it economically viable. This would mean patients travelling long distances to large departments providing high quality care to relatively few critically ill patients. Twenty-four hour consultant presence would alter the type of consultant practice in those departments and he finished with a quote from Gilbert and Sullivan; 'when everybody is a somebody, nobody is anybody'.

Contributions from the floor for the motion pointed out the evidence that senior house officers was improved by senior presence, and that by reducing medicolegal claims, costs would be reduced. Against the motion were arguments that no other specialty offered this level of cover, that consultants standing and therefore effectiveness would be reduced, and that each department would need seven consultants. If a consultant is available but not on the shop floor, only essential problems are brought to his attention and the SHOs can gain experience in decision making.

After the four main speakers had summed up a vote was taken. A vote taken prior to the debate resulted in: 36 for, 36 against and 10 undecided. Post-debate, in which three members absent at the start of the debate voted, the results were: 39 for, 43 against and three undecided.

The motion was therefore defeated by a small majority. 